\title{
Mechanics in the Production of Mandibular Fractures: Strain-Gauge Measurements of Impacts to the Chin
}

\author{
D. F. HUELKE and L. M. PATRICK
}

Department of Anatomy, The University of Michigan, Ann Arbor, Michigan, and Department of Engineering Mechanics, Wayne State University, Detroit, Michigan

Previous publications on analysis of clinical data on jaw fractures (Hagan and Huelke, 1961, and Huelke, Burdi, and Eyman, 1961 and 1962) ${ }^{1-3}$ have indicated certain definite sites of fractures from impacts to specific areas of the mandible. Results of experimental studies wherein both destructive and non-destructive testing procedures were used support certain of the clinical findings (Huelke, 1961)., 5

It is the purpose of this paper to present information on strain-gauge measurements of human mandibles under impact and to correlate these data with previous clinical and experimental findings.

\section{Materials and Methods}

In this study 6 specimens were used: 3 dry adult mandibles and 3 cadaver heads. The dry mandibles were instrumented with SR4 strain gauges using (cyano-acrylate monomer) adhesive. The gauges were firmly placed bilaterally on the medial and lateral sides of the subcondylar region, on the lingual aspect of the chin adjacent to the midline, on the lingual and buccal sides of the body at the level of the first or second molar tooth, and on the labial sides of the chin region beneath the lateral incisor or cuspid teeth (Fig. 1). Approximately five separate impacts were recorded from each gauge, and the averages of these are presented in the tables. The condyles were mounted in metal base plates with three types of fixation: (1) both condyles imbedded in metal (a low melting-point alloy);* (2) one condyle in metal and one in clay; and (3) one condyle in metal and one unsupported. The impact was to the midline of the chin; a steel ball weighing 0.146 pounds was dropped through a tube 0.69 feet in length to provide an impact energy of 0.101 foot-pounds. The line of force applied at the chin point passed vertically through both condyles and was perpendicular to the base plate in which the bone was mounted (Fig. 2).

The only variation in the testing procedures was that of the condylar fixation. Imbedding one or both condyles in metal fixed the ends of the bone, thereby preventing any movement of the condyles. The other extreme were the tests in which one condyle was completely unsupported, with the other being firmly fixed in metal. The third type involved firm condylar fixation on one side and a clay base support for the opposite condyle. Here, support was given to the condyle by the clay, but the condyle could move in this medium. These three types of condylar fixation allowed free condylar movement,

Received for publication October 8, 1963.

* Cerro de Pasco Sales Corporation, 300 Park Ave., New York City. 


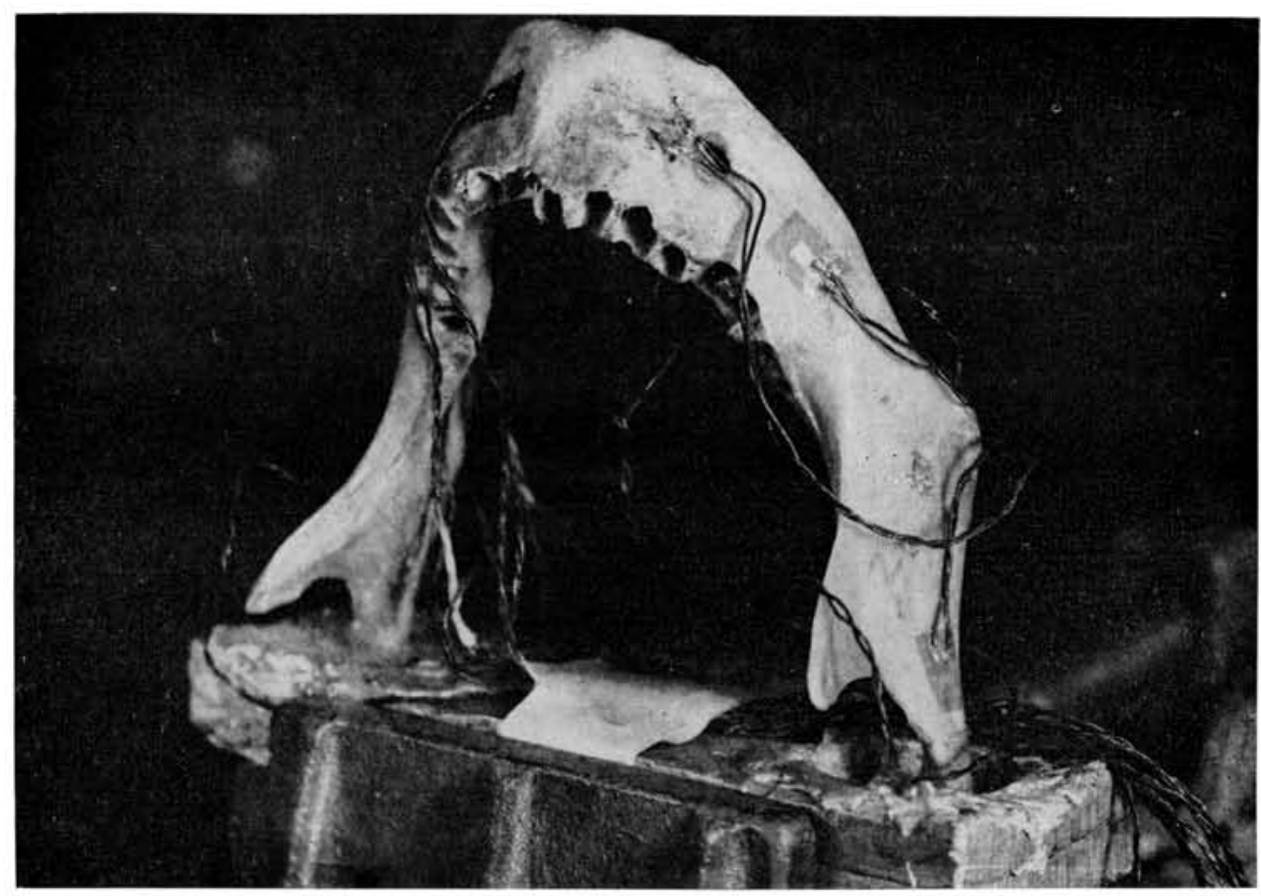

Fig. 1.-The locations of the strain gauges

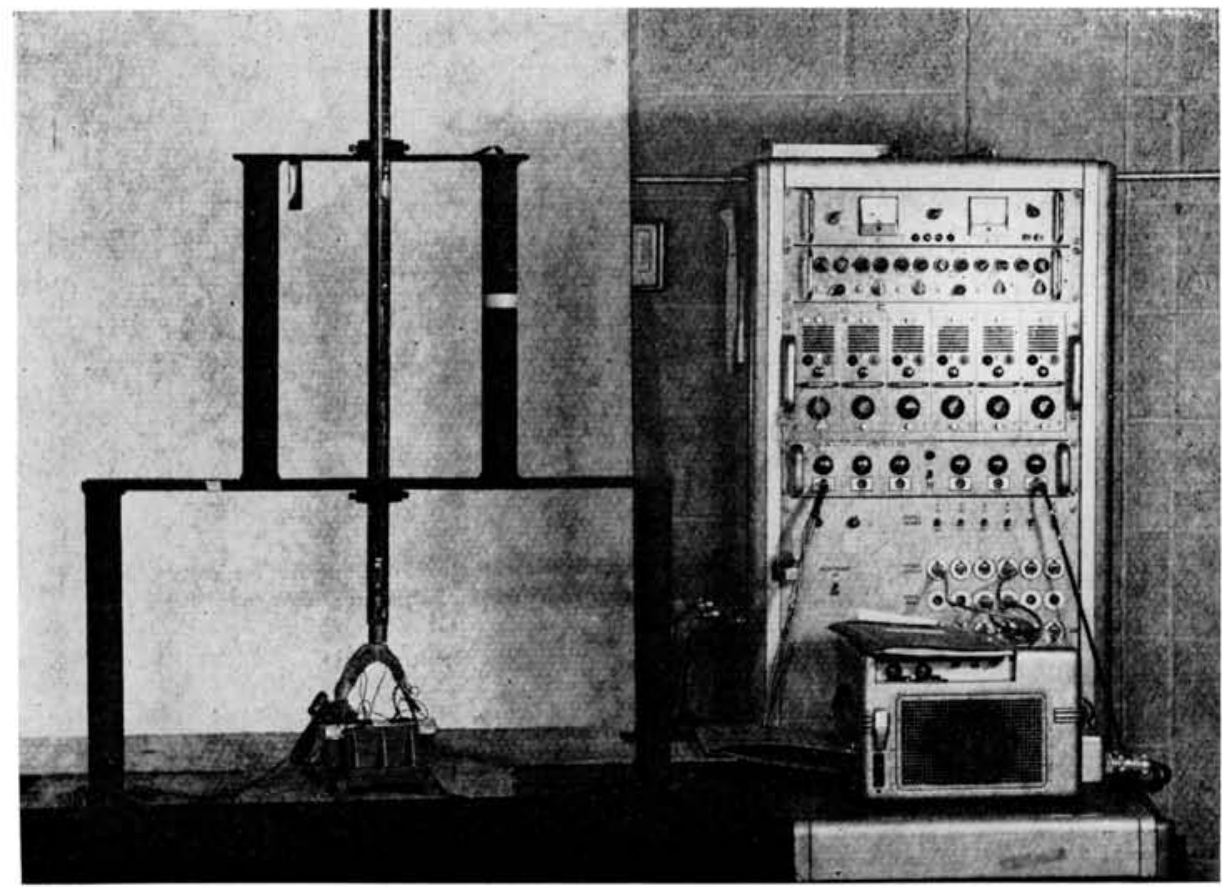

Fig. 2.-Testing apparatus showing mandible, drop tube, and recording equipment 
limited movement (in clay), or prevented movement (metal fixation). Thus loading conditions simulating those possibly occurring in the living situation were achieved.

The three intact adult cadaver heads were firmly mounted in plaster with the anterior half of the head being exposed. Chin impacts were applied through a chin point-condylar line that was perpendicular to the plaster block. Strain gauges were mounted on the lingual aspect of the chin and on the lateral side of the neck of the mandible bilaterally. One-pound weights wer used, the impact height varying from 3 to 36 inches, providing energy between 3 and 36 inch-pounds. The gauges were connected to a multichannelbridge-balance calibration unit with suitable amplifiers for operating a light galvonometer recorder.

\section{Results}

When one condyle was supported in metal and the other completely unsupported, high tensile strain was found on the lateral aspect of the subcondylar region of the immovable (fixed) condyle (Table 1). On the medial aspect of this supported condyle, high compressive values were noted.

TABLE 1

Strain in Mandibles with One Condyle FiXed (Immovable) AND ONE CONDYLE UNSUPPORTED

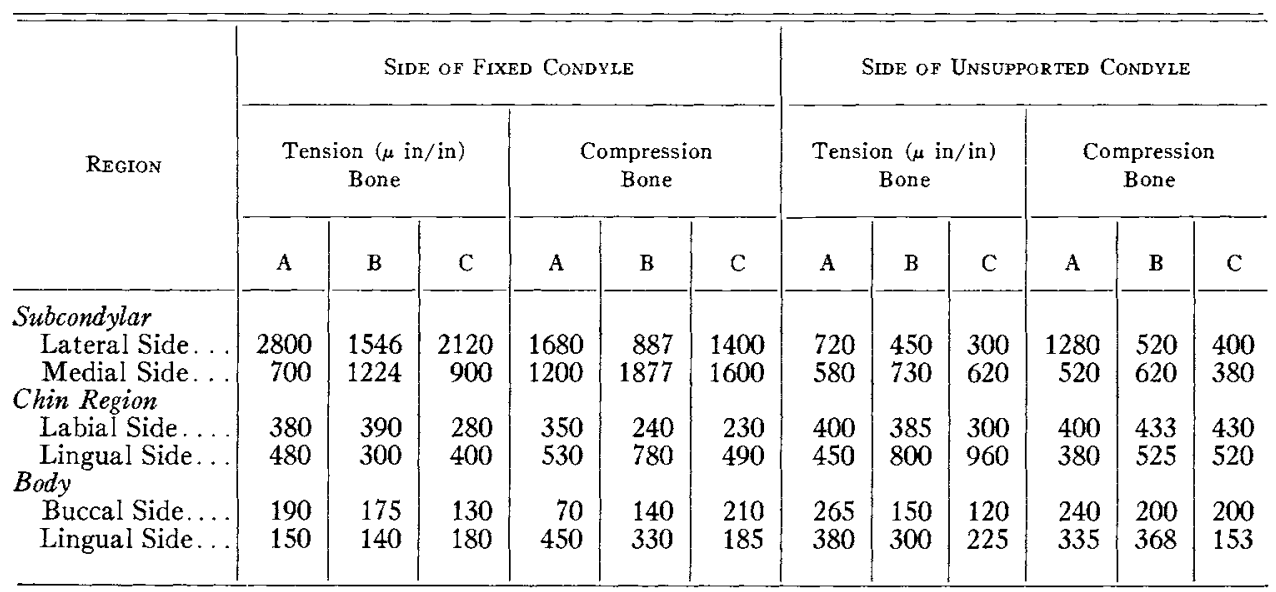

Lateral subcondylar gauges on the fixed side had maximum strain values in the order of $2800 \mu$ inches/inch tension as compared to $1280 \mu$ inches/inch compression on the unsupported side (Bone $A$ ). Bones $B$ and $C$ showed the same comparative values (Table 1). On the medial side of the mandibular neck of the fixed condyle the maximum strain of Bone $B$ was $1877 \mu$ inches/inch compression, whereas on the unsupported side the medial subcondylar gauge recorded values of $730 \mu$ inches/inch tension. Bones $A$ and $C$ were quite similar.

These findings indicated that there was a bending of the entire mandibular arch to the unsupported side, with the greatest amount of bending occurring in the region of the neck of the mandible of the fixed side.

Strain-gauge readings produced on both the lingual and labial aspect of the chin adjacent to the midline indicated alternate tension and compression stresses of approximately the same magnitude. 
On the side of the fixed condyle, greater compressive-strain values were found on the lingual side of the chin (whereas the tensile-strain values were higher on the labial side). The differences in these areas between tensile and compressive strains were, however, fairly small. However, the lingual side of the chin generally showed higher tensile and compressive values than did the labial side of the chin. Gauges in the chin area on the unsupported side showed greater tensile strain on the lingual side of the chin, with the compressive-strain values being slightly greater on the labial de. These findings indicated that the mandibular arch was widening, with the free, unsupported segment moving outward, thereby producing high tensile strain on the lingual side of the chin, whereas the fixed half showed only a slightly higher amount of tensile strain on the labial chin owing probably to the impact itself. That there were only slightly different tensile and compressive values in the area on the unsupported side indicated a vibration of the free

TABLE 2

STRAIN IN MANDIBLES WITH ONE CONDYLE FIXED (IMMOVABLE) AND ONE CONDYLE UNSUPPORTED IN CLAY

\begin{tabular}{|c|c|c|c|c|c|c|c|c|c|c|c|c|}
\hline \multirow{3}{*}{ REGION } & \multicolumn{6}{|c|}{ Side of Fixed Condyla: } & \multicolumn{6}{|c|}{ Side of Clay-supported Condyle } \\
\hline & \multicolumn{3}{|c|}{$\begin{array}{c}\text { Tension }(\mu \text { in } / \text { in }) \\
\text { Bone }\end{array}$} & \multicolumn{3}{|c|}{$\begin{array}{l}\text { Compression } \\
\text { Bone }\end{array}$} & \multicolumn{3}{|c|}{$\begin{array}{c}\text { Tension }(\mu \text { in } / \text { in }) \\
\text { Bone }\end{array}$} & \multicolumn{3}{|c|}{$\begin{array}{l}\text { Compression } \\
\text { Bone }\end{array}$} \\
\hline & A & B & $\mathrm{C}$ & A & B & C & A & B & $\mathrm{C}$ & $A$ & B & C \\
\hline \multicolumn{13}{|l|}{ Subcondylar. } \\
\hline Lateral Side. & 300 & 370 & 550 & 367 & 220 & 50 & 1030 & 350 & 130 & 412 & 361 & 380 \\
\hline Medial Side. & 194 & 320 & & 102 & 1220 & 750 & 247 & 352 & 450 & 825 & 567 & 330 \\
\hline \multicolumn{13}{|l|}{ Chin Region } \\
\hline Labial Side. & 320 & 190 & 220 & 250 & 210 & 240 & 270 & 170 & 220 & 350 & 270 & 240 \\
\hline Lingual Side. & 400 & 230 & 340 & 370 & 230 & 270 & 515 & 520 & 500 & 155 & 220 & 370 \\
\hline \multicolumn{13}{|l|}{ Body } \\
\hline Buccal Side.. & 194 & 150 & 80 & 102 & 110 & 200 & 116 & 40 & 140 & 300 & 115 & 220 \\
\hline Lingual Side & 200 & 70 & 210 & 160 & 210 & 116 & 230 & 155 & 300 & 150 & 210 & 100 \\
\hline
\end{tabular}

half of the mandible. In general the strain levels were quite low in the chin area when compared to those in the subcondylar area of the fixed side.

Bilaterally, strain-gauge readings from either the lingual or buccal aspect of the body were quite low, indicating that very little strain deformation had occurred here. On the unsupported side greater tensile and compressive strains were noted on the lingual side of the body owing to the vibratory action of this half of the mandible.

Comparing Tables 1 and 2, the marked dampening effect of the clay-supported condyle over that of an unsupported condyle can be seen. There is a decrease of more than 70 per cent in the magnitude of tensile strain on the lateral side of the subcondylar area of the supported condyle and approximately 50 per cent decrease in the compressive strain on the medial aspect of the same condyle. Likewise, there is a general decrease in the strain values of the fixed condyle by the clay-supported condyle when compared to the unsupported condyle. The clay modifies the high bending movements associated with the cantilevered bone by acting as a soft, redundant support on the outboard end of the cantilever. This reduces the total deflection of the bone, with attendant decrease in maximum strain values. 
There was also less strain produced in the chin region, and therefore less chin flattening. Bilaterally the strain levels of the body were so low that they could be neglected when considering this type of fixity and loading.

Comparing the data of the clay-supported condyle (Table 2) with that of the unsupported side (Table 1), it is apparent that there is, in general, a decrease in the amount of strain recorded from the subcondylar gauges of these sides. This decrease is thought to be owing to a change in the dynamic characteristics of the bone due to the soft redundant support and the dampening characteristics of the clay.

The rigidity of the mandibular arch when both condyles were firmly fixed, and therefore immovable, was well shown by the strain-gauge results (Table 3 ). The tensile-strain values of both right and left subcondylar regions were quite low, compared with the fixed condyle of the left-fixed-right-free tests (Table 1). This indicates that very little bending

TABLE 3

STRAIN IN MANDIBLES WITH BOTH CONDYLES FIXED (IMMOVABLE)

\begin{tabular}{|c|c|c|c|c|c|c|c|c|c|c|c|c|}
\hline \multirow{3}{*}{ Region } & \multicolumn{6}{|c|}{ LEFT } & \multicolumn{6}{|c|}{ Right } \\
\hline & \multicolumn{3}{|c|}{$\begin{array}{c}\text { Tension }(\mu \text { in } / \text { in }) \\
\text { Bone }\end{array}$} & \multicolumn{3}{|c|}{$\begin{array}{c}\text { Compression } \\
\text { Bone }\end{array}$} & \multicolumn{3}{|c|}{$\begin{array}{c}\text { Tension }(\mu \text { in } / \text { in }) \\
\text { Bone }\end{array}$} & \multicolumn{3}{|c|}{$\begin{array}{c}\text { Compression } \\
\text { Bone }\end{array}$} \\
\hline & A & B & $\mathrm{C}$ & A & B & $\mathrm{C}$ & A & B & $\mathrm{C}$ & A & B & $\mathrm{C}$ \\
\hline Subcondylar & & & & & & & & & & & & \\
\hline Lateral Side & 510 & 82 & 85 & 340 & 380 & 245 & 630 & 470 & 102 & 530 & 630 & 571 \\
\hline Medial Side & 400 & 310 & 143 & 600 & 410 & 694 & 420 & 150 & 180 & 670 & 662 & 200 \\
\hline Chin Region , & & & & & & & & & & & & \\
\hline Labial Side. . & 361 & 407 & 90 & 450 & 490 & 260 & 375 & 230 & 127 & 425 & 300 & 172 \\
\hline Lingual Side. . & 685 & 310 & 77 & 442 & 460 & 232 & 270 & 375 & 124 & 210 & 200 & 258 \\
\hline Body & & & & & & & & & & & & \\
\hline Buccal Side. & 95 & 140 & 40 & 105 & 175 & 280 & 122 & 230 & 75 & 215 & 260 & 330 \\
\hline Lingual Side. . & 165 & 115 & 150 & 365 & 230 & 125 & 155 & 215 & 194 & 240 & 230 & 77 \\
\hline
\end{tabular}

was occurring at the neck of the mandible. As might be expected, the loading appeared to be symmetrical in both subcondylar regions. In general, the strain value in the chin region approximated that of both subcondylar areas, with the strain in the body of the mandible being less than that in these other regions. Thus the chin and both condyles showed the same amount of deflection due to the chin impact. In all other instances the subcondylar strain levels were the highest.

Chin impacts to the intact cadaver heads indicated an increase in the tensile strain of the lateral subcondylar areas bilaterally, and of the lingual aspect of the chin, as greater impact energy was applied (Figs. 3-5). Greater tensile-strain values for each impact were, in general, found in the subcondylar areas than was recorded from the chin gauge.

The results of impacts to the intact heads (Specimens 2 and 3) were similar. The chin gauge in these specimens recorded very little strain deformation; both right and left subcondylar gauges recorded tensile-strain deformation of approximately the same magnitude, indicating an equal loading of the arch at each condyle. However, in Specimen 2, tensile-strain values in the subcondylar areas were two to three times as great as those recorded from Specimen 3. The difference between these is probably due to the amount 


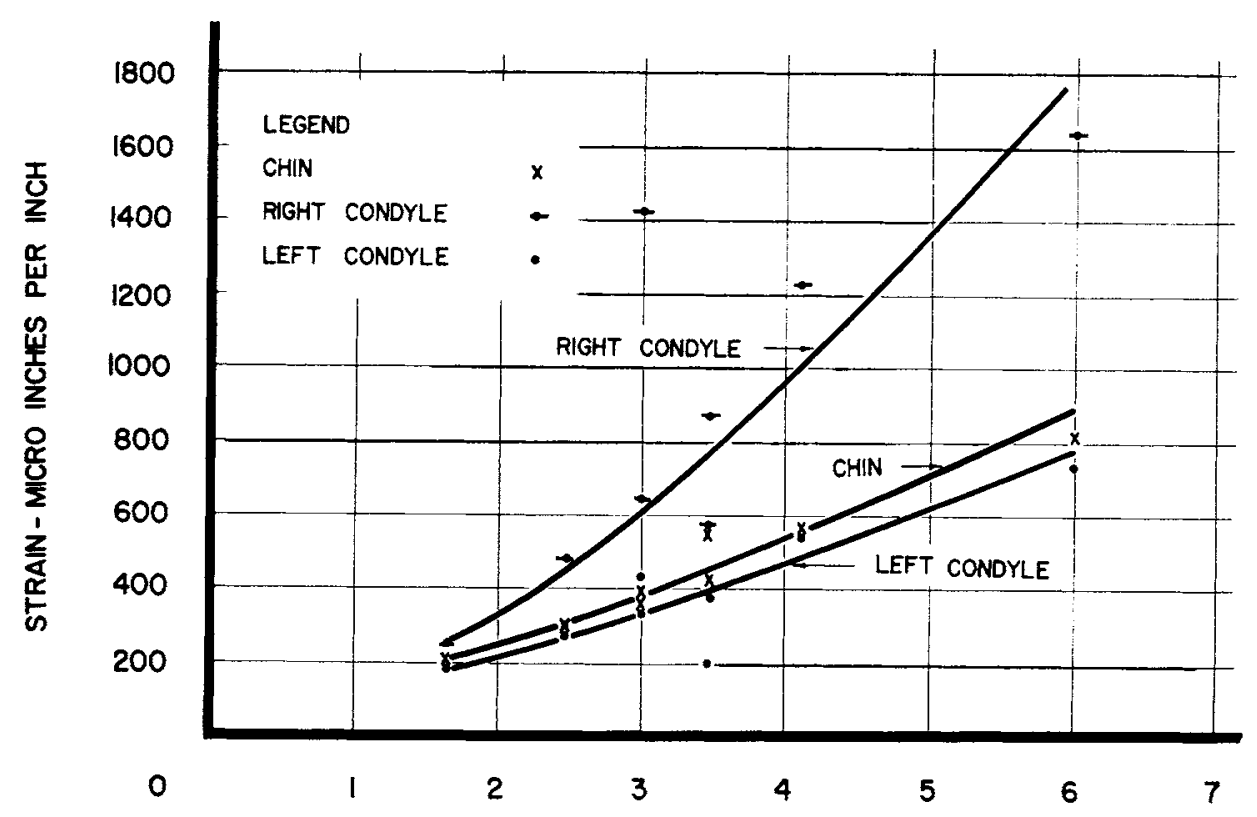

SQUARE ROOT OF ENERGY

FIG. 3. - Strain vs. square root of impact energy as recorded from chin impacts to an intact cadaver head (No. 1).

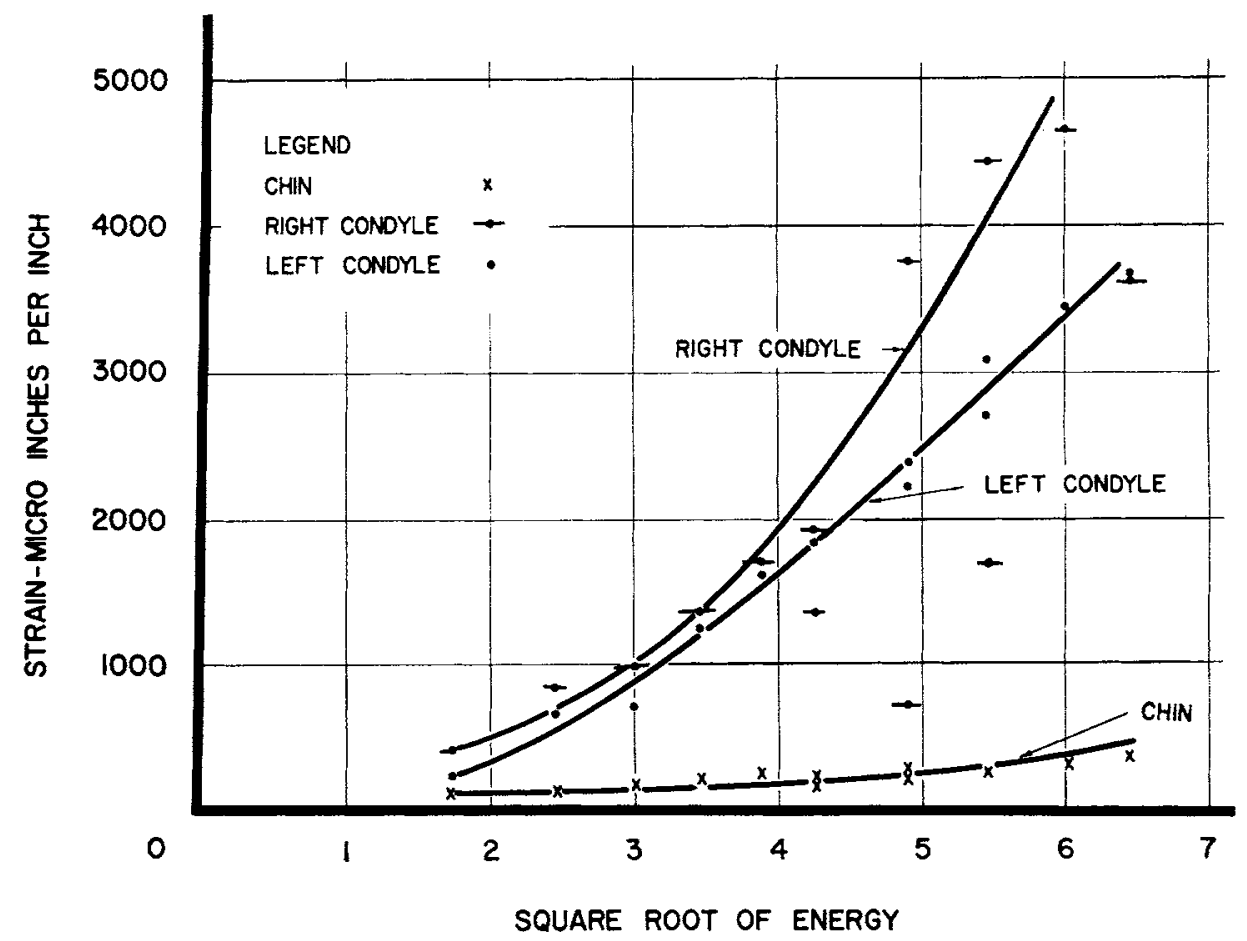

FIG. 4.-Strain vs. square root of impact energy as recorded from chin impacts to an intact cadaver head (No. 2). 
of drying of the embalmed specimen, the rigidity of the preserved material, gauge location, and minor anatomical variations.

Strain values from each location varied between specimens. In Specimen 1 the magnitude of the tensile strain of the right subcondylar gauge was twice that recorded from the left side, especially at the higher energy levels. Furthermore, tensile strain on the lingual aspect of the chin was slightly greater than that recorded for the left lateral subcondyle. Possibly this indicated an eccentric loading of the specimen with more energy going to the right side. The eccentric loading increased the bending movement in the

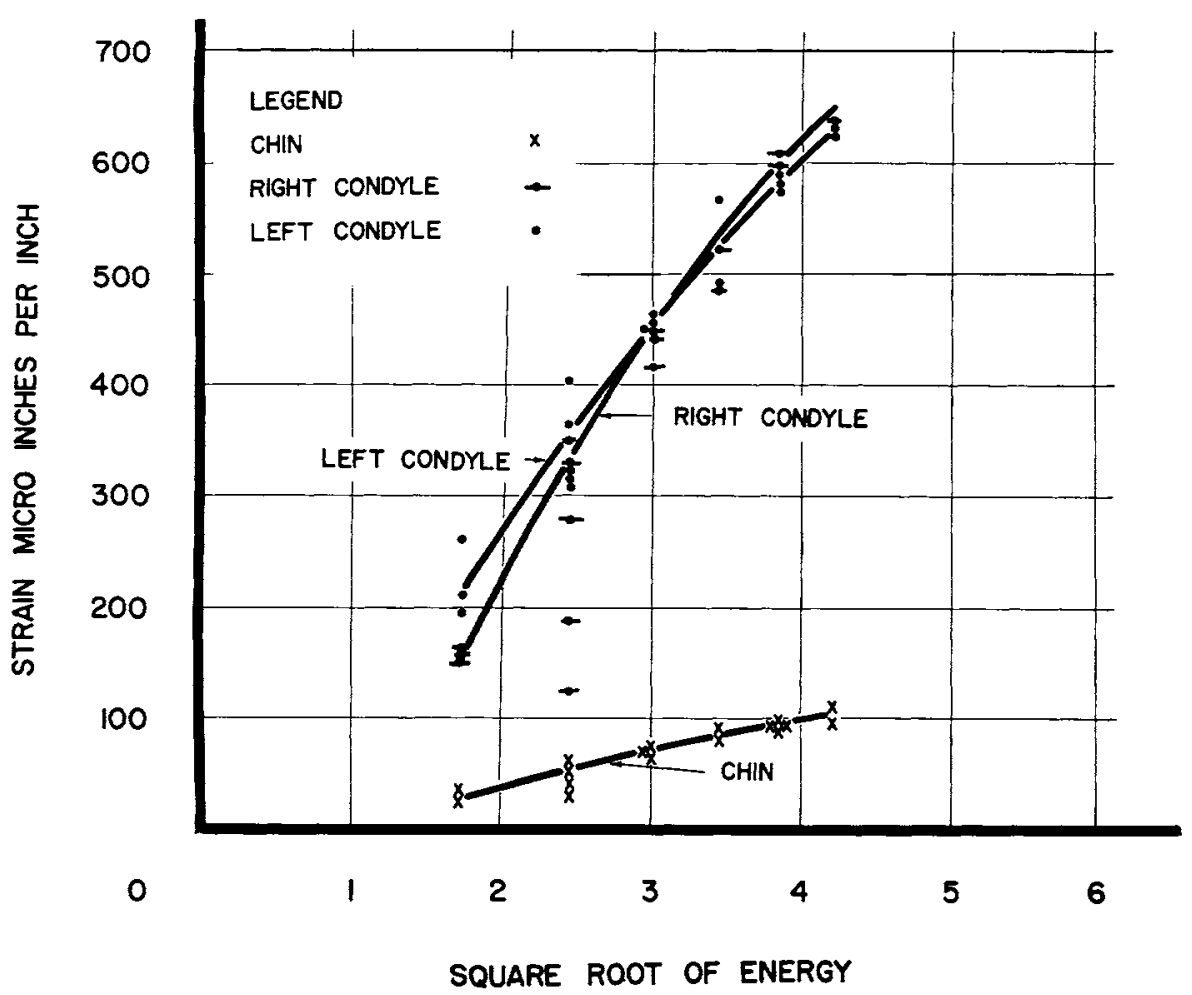

FIG. 5. - Strain vs. square root of impact energy as recorded from chin impacts to an intact cadaver head (No. 3).

chin area with an increase in the tensile strain. More probably this represented a retention of the right condyle by the self-locking characteristics of the condyle-fossa anatomy.

Preliminary investigations employing impactors of different mass have shown the strain to be a function of velocity as well as of total energy input. Consideration of the impact-test results showed the strain to be more nearly a direct function of velocity (square root of energy) than energy.

\section{Discussion}

Very little experimental work has been conducted on the mechanism of fracture production of the mandible. There are several papers wherein speculative assumptions have been made from clinical experience; however, the experimental or engineering approach to the problem has been carried out by only a few investigators. 
Messerer $(1880)^{6}$ statically loaded several mandibles that were removed from the body, and also others that were still attached to the skull. The loading point was the chin, with the direction of load passing through the condyles. He found that with pressure of approximately $200 \mathrm{~kg}$. there were fractures at the neck of the mandible on one or both sides. The rami of the mandible separated approximately $1 \mathrm{~cm}$. from each other before fracture. The total amount of pressure required to fracture a bone varied with age. He found no difference in the amount of pressure required to fracture the mandibles that were removed from the body or those that were articulated with the skull, or between male or female specimens. Matti $(1918)^{7}$ believes that the location of fractures, due to chin impacts, is dependent upon whether the mouth is open or closed at the time of the impact. If closed, the fracture is located in the subcondylar region (as evidenced by fracture and that the teeth were in contact) of the cusps of the posterior teeth. His paper has little, if any, experimental data to confirm these statements. Wassmund $(1927)^{8}$ stated that most of the fractures of the mandible are bending fractures. He stated that fractures begin on the side opposite that of the impact; thus chin impacts will cause a fracture in that area beginning on the lingual aspect. Chin impacts cause a flattening of the chin and a broadening of the arch. Thus fractures of the mandible, neck, and of the chin area are produced. Further, Wassmund has stated that the condylar neck is the weakest of all areas of the mandible. Dufourmentel $(1929)^{9}$ believed that the mechanism of production of subcondylar fractures depends upon the type of impact. A downward impact to the chin forces the condyle forward, and it strikes the articular eminence causing a subcondylar fracture. Oblique chin impacts produce a fracture of the condylar neck by forcing the ramus backwards, the condyle being retained in the joint cavity. Stromberg $(1934)^{10}$ claimed that subcondylar fractures are due to the frame of the mandible being forced outwards with the condyles being held in the articular cavities by the adjoining ligaments, and thus a subcondylar fracture is produced. Kuntscher (1935) ${ }^{11}$ used colophony, an early type of strain-sensitive lacquer, on various bones including the mandible, and indicated that there are strain patterns set up along the body of the mandible as illustrated in his paper. However, no data on testing conditions or the magnitude of strain were indicated. Walker (1942), ${ }^{12}$ citing Perthes and Borcher's work, ${ }^{13}$ claimed that there is a forward displacement of the condyles due to a chin impact, which first causes a dislocation and then a fracture of the neck.

Ueno, Oka, Miggagawa, and Kobayashi (1957), ${ }^{14}$ in one of the few experimental studies on mandibular fractures, included static and dynamic testing procedures wherein a strain-sensitive lacquer and strain gauges were used. Dried adult mandibles and acrylic models of the "same shape" were the test specimens. The number of each was not indicated in their article. Their strain-sensitive lacquer results show high tensile strain in the lateral subcondylar areas and at the angle of the mandible following symphyseal loadings. No information is given on patterns on the lingual aspect of the chin. A static load of $20 \mathrm{~kg}$. on the chin produced high tensile strain on the lateral subcondylar area $\left(101 \times 10^{-6}\right)$ and on the lingual aspect of the chin $\left(180 \times 10^{-6}\right)$. Under dynamic loadings $(40 \mathrm{~kg} . \mathrm{mm}$.) more deformation was noted on the lingual aspect of the chin and less in the subcondylar area than in the case of the static tests.

Recently one of us (Huelke, 1961), ${ }^{4}$ using a non-destructive testing procedure, found the subcondylar and lingual chin regions to be the areas of high tensile strain under dynamic loadings to the chin point. Location of the subcondylar deformation pat- 
terns, either on the medial or lateral side of the neck of the condyle, was dependent upon the type of condylar fixation. When the condyle was placed in clay (resistant, yet pliable), there were lateral subcondylar deformation patterns. Firm fixation of the condyles in metal gave small patterns on the lateral subcondyle and, at times, on the medial aspect also, indicating a vibratory movement of the condylar neck. In all tests, deformation patterns were always seen on the lingual aspect of the chin.

Additionally, fracture-producing impacts to the chin of dry, adult mandibles, as recorded by high speed cinematography, have shown that the subcondylar areas are the most frequently fractured areas of the mandible. Also chin fractures are produced in most cases with the fracture beginning on the lingual aspect of the chin (Huelke, 1961). ${ }^{5}$

Non-destructive testing procedures have shown that the subcondylar areas and the lingual aspect of the chin were high-tensile-strain regions as indicated by the deformation patterns. However, with this strain-sensitive-lacquer technique, quantitative results cannot be obtained. All that can be determined is that the strain level of the strain-sensitive lacquer had been reached and therefore the lacquer cracked. The amount of strain above this tensile level cannot be determined. The variability of the quantitative readings in this study between the bones was probably due to one of three things. One of these is the variability of the cadaver material used. Each mandible was an individual case; anthropometric measurements of each mandible indicated that they had different metric readings. Additionally, the shape of the mandibular arch itself, the thickness of the subcondylar areas, the development of the rugosity of the bone, etc., could account for different strain-gauge readings. Also, the placement of the strain gauges was not identical from bone to bone. In the subcondylar region, for example, the gauge might be placed a few millimeters higher or lower than on other bones. Thus, the cross-sectional area was different, resulting in different strain readings. This was also true for the other areas of the bone. Third, the experiments on the intact cadaver heads showed differences that could be accounted for by several variables. One, as previously mentioned, was the difference in the strain-gauge placement. This is especially true in the lingual region, where the strain gauges were placed in an area beneath the attachment of the anterior digastric muscle, and in those specimens with a greater development of the chin, the gauge could have been placed in one spot whereas with others, the exact location would have been slightly off. Additionally, some of these specimens were very pliable whereas others were quite leathery. Furthermore, after continued impacts to the chin region, the soft tissue overlying the impact site became flattened, and therefore more energy was transmitted into the bone. This could account for differences in the quantitative readings. We feel that this is exemplified in the graphs where strain is plotted versus the square root of impact energy, in that Specimen 2 showed much greater strain transmitted into the right and left condyles than in the cases of Specimens 1 and 3 .

In general, however, the graphs do show that there is a relatively straight line increase in the tensile strain as the energy is increased. Generally speaking, the lingual cortical plate does not reach as high a tensile-strain level as do the narrow subcondylar areas where the cross-sectional area is smaller. As has been pointed out, ${ }^{15}$ previous investigations on the strengths of bone, using machined bone specimens and whole bones, have shown that bone is weaker in tension than in compression. Thus, points of high tensile strain are more critical from a fracture standpoint than those of comparable high compression strain. Therefore, as shown in this paper, the subcondylar and lingual areas are 
points of high tensile strain, indicating that fractures will occur in these areas owing to direct chin impacts.

\section{Summary}

Impacts to individual mandibles with a variety of condylar supports using SR4 strain gauges in the lateral subcondylar regions and lingual cortical plates have revealed quantitative results. These data indicate that the subcondylar region, in general, is exhibiting higher tensile and compressive strains than the lingual cortical plate and that the exact amount of these strains is dependent upon the individual bone. General trends were noted wherein higher strains were found in certain localities under certain types of impact and condylar fixations from specimen to specimen. Additionally, intact cadaver heads were impacted on the chin, and here the strain-gauge readings generally showed a high tensile strain in the subcondylar regions, with lower readings from the lingual aspect of the chin.

These data confirm previous strain-sensitive-lacquer results indicating that these are the high-tensile-strain areas and also agree with certain previous clinical findings.

\section{References}

1. Hagan, E. H. and Huelke, D. F. An Analysis of 319 Case Reports of Mandibular Fractures. J. oral Surg. Anesih., 19:93-104, 1961.

2. Huelke, D. F., Burdi, A. and Eyman, C. Mandibular Fractures as Related to Site of Trauma and State of Dentition. J. dent. Res., 40:1262-74, 1961.

3. - - Association between Mandibular Fractures and Site of Trauma, Dentition, and Age. J. oral Surg. Anesth., 20:478-81, 1962.

4. Huelke, D. F. Mechanics in the Production of Mandibular Fractures: A Study with the "Stresscoat" Technique. I. Symphyseal Impacts. J. dent. Res., 40:1042-56, 1961.

5. - - High Speed Photography of Mandibular Fractures. J. biol. Photogr. Ass., 20:137-44, 1961.

6. Messerer, O. Über Elasticital und Festigkeit der menschlichen Knochen, pp. 1-100. Stuttgart: Cotta, 1880.

7. MatTi, H. Die Knochenbriuche und ihre behandlung. Bd. I pp. 26-27. Berlin: Springer, 1918.

8. Wassmund, M. Fracturen und Luxationen des Gesichtsshadels unter Berücksichtigung der Komplikationen des Hirnschadels, pp. 1-384. Berlin: Meusser, 1927.

9. Dufourmentel, M. L. Fractures of the Mandible in the Region of the Joint. Brit. dent. J., 30:620$21,1929$.

10. Stromberg, N. Fractures with Luxation of the Collum Mandibulae, and Its Surgical Treatment. Acla clitr. scand., 74:379-404, 1934.

11. Kuntscher, G. Über den Nachweis von Spannungsspitzen am menschlichen Knochengerust. Jahrbuch für Morphologie und mikroskopische Anatomie., 75:427-44, 1935.

12. Walker, D. G. Fractures of the Ramus, Condyloid, and Coronoid Processes of the Mandible. Brit. dent. J., 72:265-76, 1942.

13. Perthes, G., and Borchers, E. Verletzungen und Krankheiten der Kiefer. Neut deutsche Chirurgie, 53:1-623, 1932.

14. Ueno, T., Oka, T., Miggagawa, Y., and Kobayashi, Y. Clinical and Experimental Studies of the Location and Lines of Mandibular Fractures. Bull. Tokyo med. dent. Univ, 4:245-51, 1957.

15. Evans, F. G. Stress and Strain in Bones, pp. 3-24.5. Springfield, Ill.: Charles C Thomas, 1957. 